\title{
Employer Learning, Statistical Discrimination and University \\ Prestige
}

\author{
Paola Bordón and Breno Braga* \\ University of Wisconsin and University of Michigan
}

August, 2013

\begin{abstract}
This paper investigates whether firms use university prestige to statistically discriminate among college graduates. The test is based on the employer learning literature which suggests that if firms use a characteristic for statistical discrimination, this variable should become less important for earnings determination as a worker gains labor market experience. In this framework, we use a regression discontinuity design to estimate a $19 \%$ wage premium for recent graduates of two of the most selective universities in Chile. However, we find that this premium decreases by 3 percentage points per year of labor market experience. These results suggest that employers use college selectivity as a signal of workers' quality when they leave school. However, as workers reveal their productivity throughout their careers, they become rewarded based on their true quality rather than the prestige of their college.
\end{abstract}

JEL Classification: I21, J31, J71

Keywords: Employer Learning, Statistical Discrimination, College Selectivity.

*We would like to thank John Bound, Charlie Brown, Brad Hershbein, John Kennan, David Lam, Fabian Lange, Brian Mccall, Jeff Smith, Christopher Taber, Lesley Turner, Sergio Urzua and participants at EconCon, the University of Michigan and University of Wisconsin labor workshops for their valuable comments. The authors can be contacted by email: bordon@wisc.edu and bgbraga@umich.edu. 


\section{Introduction}

Labor markets are characterized by incomplete information on workers' productivity (Spence (1973)). There are some characteristics of workers, such as labor market ability, that are important for performance on the job but are not easily observable by employers. In this context, firms often have to make judgments on workers' unobservable quality on the basis of the available information. Within this framework, statistical discrimination is defined as employers using a group identity of workers to infer their unobservable quality.

The most traditional group identity studied in the statistical discrimination context is race (Phelps (1972) and Aigner and Cain (1977)). In this literature, the racial wage gap is justified not because employers are prejudiced against a particular race but because they use race identity to predict the unobservable quality of workers. More recently, evidence was found that firms use schooling (Farber and Gibbons (1996), Altonji and Pierret (2001) and Lange (2007)) or even information on lay-offs (Gibbons and Katz (1991) and Hu and Taber (2011)) to statistically discriminate workers.

In this paper we study a new dimension of statistical discrimination: we investigate if firms use the prestige of the university attended by a worker to predict his or her unobservable labor market quality. We believe that college prestige satisfies the typical features of group identity that might be used for statistical discrimination for two main reasons. First, this information is easily accessible to firms: workers use the university name in their resumes and prestigious universities are widely recognized in the labor market. Second, there is evidence that more talented individuals attend more prestigious universities (Hoxby (1998) and Dale and Krueger (2002)). Overall, elite universities have a very competitive application process and tend to select higher quality candidates. ${ }^{1}$ Within this framework, it is natural to believe that firms use university prestige in order to infer the unobservable labor market quality of workers.

In order to test if employers use university prestige as a signal of workers' unobservable quality, we rely on the statistical discrimination and employer learning (EL-SD) literature (Altonji and

\footnotetext{
${ }^{1}$ As it will become clear later, the underlying assumption is that universities are better at screening candidates than firms.
} 
Pierret (2001)). ${ }^{2}$ The underlying assumption is that the imperfect information about a worker's quality tends to disappear as firms observe his or her on-the-job performance. Therefore, as a worker gains experience in the labor market, employers rely less on observable characteristics and payments are made in accordance with the worker's true productivity. Based on this assumption, Altonji and Pierret suggest a statistical discrimination test where the impact of the group identity on earnings should decrease with experience and the impact of ability measures that are not observed by employers but are observed in the data should increase with experience. ${ }^{3}$

Within this framework, this paper uses data from Futuro Laboral of the Chilean Ministry of Education to test if firms statistically discriminated workers on the basis of college prestige. This data satisfies the purpose of the paper for several reasons: first, it follows different cohorts of college graduate workers from Chile in their first years in the labor market, the period in which most of the employer learning happens (Lange (2007)). Second, the data presents information on labor market outcomes such as earnings from administrative data and we can identify workers that graduate from elite universities. Finally, the data contains information on the scores of the centralized admission test to universities in Chile. This information will be useful for providing both a measure of a worker's ability not easily observed by firms and as a running variable in the regression discontinuity test we will suggest.

We use this data to perform the EL-SD test in two different ways. We first follow the EL-SD test proposed by Altonji and Pierret (2001) and estimate an earnings equation where both returns to graduating from a prestigious university and unobservable ability measures can change with experience. We use information on math and language scores of the university admission test as the measure of workers' ability not easily observed by firms. We present some further evidence that these are good measures of hard-to-observe correlates of productivity.

In addition to the traditional EL-SD test, we take advantage of the centralized admission process to college in Chile to suggest a statistical discrimination test based on regression discontinuity

\footnotetext{
${ }^{2}$ Other important papers in this literature include Lange (2007), Schönberg (2007), Arcidiacono et al. (2010), and Mansour (2012).

${ }^{3}$ Altonji and Pierret use AFQT test, father's education and and wage rates of older siblings as measures of ability correlates that are hard to observe by the firm.
} 
design. Using information on the admission test scores we are able to identify workers who were just above or just below the thresholds to be admitted in the two most prestigious universities in Chile. We propose an EL-SD test that compares how the earnings differential between these two groups changes as workers gain experience in the labor market. The suggested RD test aims to disentangle our estimates from the effects of other factors that might be used for statistical discrimination, such as family socioeconomic status, which are correlated to graduating from a prestigious university but not observed in the data. ${ }^{4}$

We find evidence that firms statistically discriminate using both the traditional EL-SD and the regression discontinuity test. Following the traditional EL-SD test we estimate that college graduates from the two most selective universities in Chile earn on average $24 \%$ more after graduation than less prestigious university graduates. However, we find that this wage differential decreases by 1.7 percentage points by year of experience. We also estimate that the math component of the admission test, our measure of ability not observed by firms, increases on importance for wages as workers accumulate experience. These results are consistent with the predictions of EL-SD test proposed by Altonji and Pierret (2001).

The regression discontinuity design approach provides further evidence for statistical discrimination. We estimate that workers just above the admission cutoff to the two most prestigious universities in Chile earn on average $12 \%$ more than those just below the cutoff in the first year after graduation. However, this wage premium tend to decrease by 2 percentage points by year of experience in the labor market, to the point that we cannot reject a zero earnings differential between these two groups of workers 4 years after their graduation. We interpret these findings as evidence that firms rely less on college prestige as workers reveal their quality to employers.

Based on these findings, this paper contributes to different dimensions of the existing literature. First, this paper is a contribution to the EL-SD literature because we study statistical discrimination on the basis of a different identity. While there is an extensive literature that analyzes the use of

\footnotetext{
${ }^{4}$ Kaufmann et al. (2012) and Hastings et al. (2013) are two recent papers that have also explored the regression discontinuities generated by the centralized admission process to universities in Chile. Kaufmann et al. (2012) looks at effect of graduating from a elite university on marriage outcomes and Hastings et al. (2013) studies labor market returns to college admission. None of these papers explore how the selective university wage premium changes throughout a worker's career, that is the main object of interest of this paper.
} 
race, gender, and schooling, we are one of the first papers to study whether firms use prestige of college to statistically discriminate workers. ${ }^{5}$ Furthermore, to the best of our knowledge, our paper is the first to propose an employer learning-statistical discrimination test based on a regression discontinuity design.

Second, we contribute to the literature which studies the effect of graduating from an elite university on labor market outcomes. There is an extensive series of papers that estimate the returns to graduating from a selective university on earnings (Brewer et al. (1999), Hoxby (1998), Dale and Krueger (2002), and Black and Smith (2006)), including papers that have used a regression discontinuity design (Saavedra (2008) and Hoekstra (2009)). The overall finding is that there is a positive effect of graduating from a prestigious college on earnings. ${ }^{6}$ While there is big effort in the literature to overcome the selection bias associated to attending a prestigious university, little attention has been given to the mechanisms that generate the college selectivity wage premium. ${ }^{7}$

Different from past work, in this paper we shed some light on the reasons for why workers from prestigious universities receive higher wages after graduation. On one hand, attending a selective university could be associated with receiving better instruction and having more accomplished peers. In this context, prestigious universities have an advantage of increasing a worker's productivity in comparison to less prestigious universities. On the other hand, the main effect of attending a selective university might be to signal to employers an unobservable inherent ability of a worker. In this context, the extra value added from a selective college education might not be significantly higher than that from a less prestigious university.

We believe that our finding of a rapid decrease in the elite college premium for workers with

\footnotetext{
${ }^{5}$ To the best of our knowledge, Lang and Siniver (2011) and Hershbein (2013) are the two other papers that have addressed this issue. Lang and Sniver have a similar approach to estimate how returns to attending a elite university in Israel changes with labor market experience. However, the authors are unable to properly exploit the regression discontinuity in the college admission.

${ }^{6}$ The only exception is Dale and Krueger (2002) who find no wage premium from attending a selective college. It is interesting to note that the authors estimates the wage premium approximately 15-19 years after a worker's graduation from college. The zero effects later in a worker's career does not contradict the empirical findings of this paper.

${ }^{7}$ Pop-Eleches and Urquiola (2013) is one of the few papers that have discussed the benefits from attending a higher quality school. Their paper address the behavior effect of students, parents and teachers in response to a student admission to better secondary school. Nevertheless, the paper has little to say about the impact of attending a higher quality school on labor market outcomes.
} 
similar pre-university characteristics is evidence for signaling mechanisms rather than productivity mechanisms. It is hard to argue that the additional value added by a selective university education would depreciate so rapidly in the first years of a worker's career. A more compelling explanation is that workers around the admissions cut-off have similar post-schooling productivity but are paid differently because employer use college selectivity as signal of unobservable characteristics. However, as the imperfect information about a worker's quality tends to disappear as firms observe on-the-job performance, the signaling effect of graduating from a prestigious university tend to decrease for workers with similar productivity.

\section{Institutional Framework}

Higher education in Chile comprises three types of institutions: Universities, Professional Institutes (IPs), and Technical Formation Centers (CFTs). Universities provide the highest degree of learning, combining teaching, research and outreach activities; they teach accredited degree programs $(2.5$ to 4 years) and award academic degrees (5 to 7 years). Professional Institutes are in charge of granting professional degrees other than those awarded by universities, and they are also authorized to grant higher education technical degrees in areas where this is required. Technical Formation Centers are intended to equip higher level technicians with the competencies and skills needed to respond to the needs of industry in the public and private sectors.

Universities can be divided into two main categories: traditional and non-traditional institutions. Traditional institutions comprise the oldest and most prestigious universities created before 1981, and those institutions that derived from the old universities (created after 1980). Traditional establishments consist of 25 fully autonomous universities coordinated by the Council of Chancellors of Chilean Universities (CRUCH) and are eligible to obtain partial funding from the state. They employ a single admission process: the University Selection Test (PAA) ${ }^{8}$. This test is made up of three compulsory sub-tests including language, mathematics, and history and geography of Chile. Additionally, depending on which programs they are planning to apply to, students may be required

\footnotetext{
${ }^{8}$ In 2004 the university selection test was modified and it is now called PSU.
} 
to take the following specific PAA tests: advanced mathematics, physics, chemistry, biology, and history.

The time-line of the admission process into traditional universities happens as described in figure 1. First, students take the PAA test and after receiving their score they make their application choices. Students apply to a major and university (or program) simultaneously and can only apply to 8 programs, ranking them up by preferences. The only criterion used for admission in the traditional universities is the score in the PAA. This final admission scores consists of a weighted average of the compulsory and major specific tests and high school GPA, with each program setting its specific PAA weights. ${ }^{9}$ The number of vacancies for each program is announced before the application process and programs fill their vacancies solely based on the final weighted scores. The admission score cutoff is defined by the score of the last student admitted into a program and it is not known before the application decisions and therefore students cannot manipulate which side of the cutoff on they fall on. ${ }^{10}$

Non-traditional universities were created after 1981, have no state financial support and might not necessarily use the PAA score to select their incoming students. Nevertheless, the anecdotal evidence is that the majority of students willing to attend higher education in Chile take the PAA at the end of high school independent of the university they are planning to attend. The test is relatively inexpensive and administrated throughout the country.

All higher education institutions charge tuition and fees. However, for those students enrolled in one of the traditional universities, solidarity credits and scholarships are available. Competition in these markets, particularly for undergraduates, is often geographically circumscribed to local and regional markets, and it can be more or less intense depending on the institution. As of 2001, the Chilean higher education system consisted of 60 universities (25 traditional universities and 35 new private universities without direct public subsidy), 42 professional institutes (all of them private),

\footnotetext{
${ }^{9}$ For example, engineering in a prestigious university requires $20 \%$ of mathematics, $10 \%$ of language, $10 \%$ of history, $20 \%$ high school GPA, 30\% specifics mathematics, and 10\% physics. The final score to the same major in a different university might requires different weights.

${ }^{10}$ Students could use the admission score cutoff of previous years as a reference. Given the variation of the admission cutoff overtime and the possibility to apply to 8 different programs, we believe that students with marginal scores to be admitted in prestigious university tend to to apply to these competitive programs.
} 
and 117 private technical formation centers.

The increasing enrollment in higher education has led to an increasing number of graduates in the last two decades. In 1995, 24,400 graduates entered the labor market, whereas in 2000 around 42,000 graduates did, and in 2005, 71,170 new graduates were entering the job market. This means than in ten years the number of graduates has almost tripled. Traditional universities have more than doubled the number of graduates they produce, but private universities have increased by 6.7 times their number of graduates.

\section{Data}

The data to be used in the study comes from Futuro Laboral, a project of the Ministry of Education of Chile that follows individuals over the first years of labor market experience after graduating from higher education programs. The panel data set matches tax returns with transcripts of students' majors and the institutions they graduated from. The unit of analysis concerns only those who graduate from both traditional and non-traditional universities; those who have stopped studying or did not continue their studies after graduating from high school are not in the sample. Income information is available between the years 1996 and 2005. We have data for the 1995, 1998, 2000 and 2001 graduating classes. ${ }^{11}$

The information provided by the Internal Revenue Service (SII) comprises age, sex, name of the institution that individuals graduated from, major, the year of graduation, annual income reported in tax returns, city or cities of employment, number of employers and economic sector. The raw data contains every worker in Chile that had positive earnings between 1996 and 2005, even those who exempt from tax. ${ }^{12} 13$ For a random sub-sample, the Ministry of Education gathers

\footnotetext{
${ }^{11}$ Note that the cohorts are observed for different length of time. For example, while we observe 10 years of labor market experience for the 1995 graduation class, we only 4 years of labor market experience for the 2001 . Unfortunately, the project was deactivated and the income data for more recent years was not not collected.

${ }^{12}$ Note that in Chile, married couples must fill their taxes separately.

${ }^{13} \mathrm{~A}$ concern is that part of the individual from prestigious universities might go to graduate school after finishing their baccalaureate studies and therefore would be omitted in the earnings sample. However, the fraction of workers that go to graduate school in Chile is very low. Using data from the National Socioeconomic Characterization Survey in the year 2000 , we find that only $0.65 \%$ of $25-34$ years old individuals with a bachelor degree were enrolled in graduate school or had obtained a graduate degree.
} 
information about the PAA score, high school grades and the institutions students graduated from high school. As the PAA scores have an important role in both the traditional EL-SD and regression discontinuity analysis, we restrict our study to this sub-sample.

The wage measured in the sample is the annual income that comes from jobs and services provided by the individual. ${ }^{14}$ We use consumer price index (IPC) as a deflator to compute real wages. The experience variable is computed as the number of years an individual has income and has paid taxes after graduation. The final sample consists of 58,477 individuals and 322,688 observations.

We divide universities into two groups: selective and non-selective universities. The selective universities comprises two of the oldest and most prestigious universities in the country. These schools attract students with the highest PAA scores and therefore are the most selective schools in the country. The programs of these two universities have also been consistently ranked among the highest in Chile and their prestige is well recognized nationwide. ${ }^{15}$ See Table 1 for descriptive statistics regarding these two groups. As expected, selective universities have on average higher scores in Math and Language components of the PAA tests, and their students have higher high school grades. We also see that $11 \%$ of selective universities students went to a private high school, compared to $7 \%$ from non-selective universities. We also plot in the distribution of language and math PAA scores for college graduates from selective and non-selective universities on figures 2 and 3 respectively. One can see from the figures that the language and math scores of graduates from selective universities are concentrated at the higher end of the distribution. Finally, we show in Table 2 that workers from the two selective universities have on average higher earnings than those from the less prestigious schools.

\footnotetext{
${ }^{14}$ We do not have information on weeks or hours worked in the sample and for this reason we cannot explore how much of the annual income increase is due to changes in hours or week of work. Nevertheless, workers with a bachelor degree in Chile present both a high employment attachment and the majority work full time. Using the National Socioeconomic Characterization Survey in the year 2000, we find that $86.7 \%$ of $25-34$ years old individuals with a bachelor degree work are employed in the period of the interview and from those, $88 \%$ work more than 35 hours per week.

${ }^{15}$ Due to a confidentiality agreement with the Ministry of Education, we cannot provide the name of these two organizations.
} 


\section{Traditional EL-SD Test}

We first investigate statistical discrimination on the basis of university selectivity by following the employer learning statistical discrimination (EL-SD) test suggested by Altonji and Pierret (2001). The main idea of the traditional EL-SD test is that if employers cannot observe a prospective worker's productivity directly, they might use easily observable correlates of productivity, such as schooling or university prestige, to predict a worker's productivity. However, as workers spend time in the labor market, more information about their productivity is available and firms might rely less on observables to reward workers. ${ }^{16}$

Within this framework, the EL-SD test consists of a linear regression in which earnings depend on the observable characteristics that might be used for statistical discrimination, ability correlates observed in the data but that are not observed by employers $(z)$, and their interaction with experience. ${ }^{17}$ If firms statistically discriminate on the basis of the observable variable, we should observe two effects. First, the coefficient on unobserved ability $z$ should increase with experience. In other words, as workers gain experience, more information about their true ability is revealed and consequently wages increasingly reflect the correlation between wages and $z$. Second, the returns to the observable characteristic used for statistical discrimination should decrease with experience since employers rely less on these variables to predict productivity of their workers. Consequently, allowing the $z$ variable to interact with experience lowers the coefficients of the observable characteristic for experienced workers more than the less-experienced workers.

In the context of this paper, the traditional EL-SD test proposed by Altonji and Pierret (2001) can be represented by the equation below:

$$
w_{i, t}=\beta_{0}+\beta_{s} s_{i, t}+\beta_{z} z_{i, t}+\beta_{s, x}\left(s_{i, t} \times x_{i, t}\right)+\beta_{z, x}\left(z_{i, t} \times x_{i, t}\right)+f\left(x_{i, t}\right)+\beta_{\Phi}^{\prime} \Phi_{i, t}+v_{i, t}
$$

\footnotetext{
${ }^{16}$ The EL-SD test suggested by Altoji and Pierret assumes that all employers are risk neutral, have access to the same information, and there is a spot market for labor. The importance of these assumptions rely on the fact that competition in labor markets ensures that wages reflect expected productivity of workers conditional on commonly observed information.

${ }^{17}$ Altonji and Pierret use AFQT test, father's education and and wage rates of older siblings as measures of $z$.
} 
where $w_{i}$ is the $\log$ wage of individual $i$ in period $\mathrm{t}, s_{i}$ is a selective university dummy, $z_{i}$ is the ability measured not observed by firms, that will be represented by the math and reading components of the standardized university admission test PAA, $x_{i}$ is experience in the labor market, and $\Phi_{i}$ is the vector of controls, including university majors and a dummy for private high school. Based on this equation one can test statistical discrimination on the bases of $s_{i}$ : the interactions between $s_{i}$ and experience is non-increasing, i.e. $\beta_{s, x} \leq 0$, and the interaction between ability $z$ and experience is non-decreasing, i.e. $\beta_{z, x} \geq 0$. Obviously, if employers have full information on the ability and productivity of workers, then $\beta_{s, x}=\beta_{z, x}=0$.

An important innovation of this paper is that we use math and reading components of the PAA as a measure of ability correlates not easily observed by firms. We have a couple of reasons to justify our choice. First, these are the components of the PAA test formulated to measure inherent abilities of applicants. Their purpose is to give opportunities for those who didn't have adequate formal education to demonstrate their capacity in the admission process to traditional universities. Second, there is evidence that employers do not have access to the PAA score at the moment of setting wages. According to an interview with Juan Swett (2011), the CEO of "www.trabajando.com" which is the biggest job search web portal in the country, most Chilean employers do not ask for the PAA score in the resume of prospective workers. A justification for this statement is that, in contrast to universities, employers do not have access to the full distribution of PAA scores. Therefore, the absolute value of the PAA score for a single worker might be not very informative to a firm.

We present the estimation of equation (1) in table 3. All the standard errors are clustered at the individual level and we use White-Huber corrections for possible heteroscedasticity. Actual experience is modeled with a cubic polynomial and we control for gender, majors, private high school indicator and year dummies. In order to facilitate the interpretation of the coefficients, we standardize the PAA score by test year.

Column 1 of table 3 reports the results of the estimation when the interaction of experience with ability and selective university dummy are excluded. It turns out that going to a traditional, 
prestigious and very selective university has a positive and important effect on earnings. In exact terms, it increases log wage in 0.196. Notice also that our proxy for innate ability, PAA has a positive and statistically significant effect on earnings. An increase in one standard deviation in the language PAA test increases wages in $3 \%$, whereas an increase in one standard deviation in the math test rises wages in $7.5 \%$.

In column 2 we introduce the interaction between the selective university dummy and experience. If university selectivity provides a signal of workers ability to employers, we should expect that the earnings of recent college graduates from prestigious universities to be higher relative to those from less selective institutions. However, we should not observe an increase in the importance of college selectivity on earnings as workers gains experience if employers learn about a worker's true ability across time. This is in fact the finding of the equation presented in column 2 , where we estimate a coefficient of $-0.009(0.0027)$ for the interaction between the selective university and experience. ${ }^{18}$

The important result of table 3 comes from column 3 where we add PAA scores interacted with experience to capture the idea of statistical discrimination and employer learning. The coefficient on selective universities is 0.242 , which is large and statistically significant. That is, the premium to a selective university on earnings with respect to a less selective one at the beginning of the worker's career is $24 \%$ in term of log wages, but it decreases with experience. Therefore, the effect of attending the most selective and oldest universities on earnings decreases over time supporting the theory of the EL-SD model. ${ }^{19}$

Finally, the coefficient of 0.0545 (0.0062) on standard math PAA and the coefficient of 0.0072 (0.0013) on standard language PAA interacted with experience suggests that the effect of a onestandard-deviation shift in standard math PAA score raises wages $7.2 \%$ in ten years, which is consistent with the employer learning thesis that wages increasingly reflect productivity, augmenting

\footnotetext{
${ }^{18}$ Both Farber and Gibbons (1996) and Altonji and Pierret (2001) estimate insignificant effects of interaction between schooling and experience using the the same specification. Our estimates are small but significant what might be justified by the grater number of observations we have.

${ }^{19}$ The fact that the coefficient of universities times experience is negative while the coefficient of standardized PAA times experience is positive decreases the possibility that the latter is associated with training. Human capital models and on-the-job training empirical evidence suggest that education and ability make workers most likely to be trained and that more educated and more able workers receive more training. If this is the case, then we expect that the effect of going to college and the PAA score on wages would both increase over time.
} 
the correlation between wages and ability. The positive but insignificant effect of the interaction between language PAA and experience can be justified by the fact that language and communication skills are more easily observed in interviews and the hiring process at the beginning of a worker's career. Therefore there is not much learning to happen regarding this attribute with experience.

Figure 4 presents further empirical evidence of the decreasing returns to graduating from a selective university in Chile. Each circle of the graph represents an estimation of the coefficient of the selective university dummy controlling for math and language scores within each experience group. Note that the impact of graduating from a selective university is greater for recent graduates $(21-26 \%)$ but tends to slowly decrease in the first years of a worker's career. Note that the wage premium finally stabilizes at $10 \%$ after the 8 -th year of labor market experience. One could interpret this trend as that it takes about 8 years for employers to learn a worker's ability and the wage premium remaining after that represents the permanent productivity gain from attending a selective university in Chile.

In table 4 we present a robustness check for the evidence that firms statistically discriminate workers on the basis of university selectivity. In columns (1) and (2) we include an interaction of female and private high school indicators with experience on the main model estimated in table 3. As presented in table 1, these are pre-treatement variables that are correlated to graduating from a prestigious university and observed by firms in the beginning of a worker career. Therefore, one could claim estimated change of the effect of graduating from a selective university with experience only reflects the difference between earning profiles of males and females, for example. However, the coefficients of graduating from a selective university and its interaction with experience estimated in both model (1) and (2) are very similar to the one estimated in table 3 . We conclude that our estimations do not reflect the difference between male and female earnings-experience profile or the difference in career paths of workers that graduate from private or public high school.

Finally, in table 5 we test how robust our results are to the definition of which universities are selective. For this purpose, rather than using an indicator that a workers graduated from one of the two most prestigious universities from Chile, we use a continuous measure of prestige for all 
colleges. Precisely, we assign to each university its quality score as presented in the "Que Passa" college ranking, one of the most widely recognized in the country, for 2011. In this framework, we estimate how earnings vary with this score, defined as university quality index in the table, its interactions with experience and the remaining controls. The results from this estimation are very similar to the ones presented in table 3: there are gains from attending a more prestigious university for recent college graduates but these returns tend to decrease with work experience. We also estimate that returns to math PAA scores increase with experience in this specification.

\section{Regression Discontinuity Test}

In order to provide more compelling evidence for statistical discrimination based on college prestige, we use a regression discontinuity (RD) design. The basic idea is to compare how the earnings of those just above and just below the cutoff for admission to the most selective universities in Chile change as workers accumulate experience in the labor market. The identification assumption is that other factors that could affect earnings are continuous at the admission cutoff and students have limited power to manipulate on which side of the admission cutoffs they might fall. ${ }^{20}$

We believe that regression discontinuity design has a few advantages over the traditional EL-SD test. While a traditional test only establishes correlations between graduating from a prestigious university and earnings, the estimates from the RD design can distinguish the effect of graduating from a top university from other confounding factors. In this context, one can interpret the discontinuous jump in earnings at the admission cutoff as the causal effect of admission to a prestigious university on earnings for the workers around the admission cutoff.

This difference is particularly important in the EL-SD context if there are factors that firms might use for statistical discrimination that are correlated with college selectivity but are not observed in the data. For example, the traditional EL-SD test might confound statistical discrimination based on family socioeconomic status and statistical discrimination based on college

\footnotetext{
${ }^{20}$ Students can retake the test next year, but they cannot retake the test after they got their results the same year, which decreases the probability of manipulation.
} 
prestige since these factors are intrinsically related. In addition, the RD test does not require functional form assumptions regarding the relation between observed and unobserved characteristics and productivity as presented in the traditional EL-SD test.

\subsection{The Admission Process and the RD Design}

Our data contains information on the year a student took the PAA test, his or her scores on each component of the test, the college he or she graduated from and the major. We do not observe application decisions and therefore have to make extra assumptions and sample restrictions to perform the regression discontinuity design. Precisely, we restrict the data to individuals who graduated with engineering, business, medical and law degrees (competitive majors) and assume that these workers would prefer to graduate with these majors in a least prestigious university rather than study a different major in a prestigious university. Under this assumption, we can interpret that workers just above the admission cutoff (competitive major at prestigious universities) are those who were accepted to the highest program of their preference and those below the threshold (competitive major in less prestigious college) are those who were accepted to the second highest program of their preference. We find evidence that this is a plausible assumption. First, these are the programs with highest admission cutoffs and therefore should be top choices of applicants. Second, there is a positive wage differential between workers with the competitive majors in less prestigious university and workers with less competitive major in prestigious university. We interpret this as evidence that students have incentives to study engineering, business, medical or law degree at a less prestigious rather than other major in a prestigious university.

Using additional data on the PAA weights used by these programs in the two prestigious universities we are able to reconstruct the final weighted score for all individuals in the restricted sample. ${ }^{21}$ As a result, we derive Univ1.Score $e_{i}$ and Univ2.Score $_{i}$ that represents the PAA weighted score of individual $i$ at prestigious university 1 and 2 respectively.

\footnotetext{
${ }^{21}$ We were only able to obtain PAA weights for years starting in the year 2000. In order to construct final scores for individuals that too the PAA prior to 2000, we assume that programs used the same weights for previous years. The evidence is that programs do not change weights over time.
} 
Given the possibility that a student can be accepted in two, one or neither of the prestigious universities, we define the running variable used in the RD as follows:

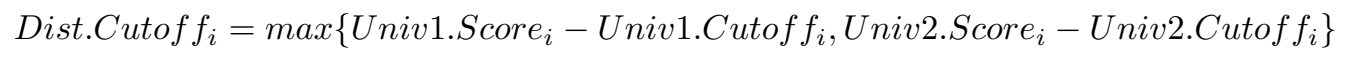

where Univ1.Cutof $f_{i}$ and $\operatorname{Univ2.Cutoff} f_{j}$ are the admission score cutoffs used by universities 1 and 2 for individual $i$ 's major in the year of application to college. Note that individuals with Dist.Cutof $f_{i}$ slightly greater than zero were barely admitted to at least one of the two prestigious universities and individuals with slightly lower than zero were barely reject by both schools. ${ }^{22}$

In the RD design we will be interested in the following object:

$$
\tau_{t}=\frac{\lim _{\text {Dist.Cutoff } \downarrow 0} \mathbb{E}\left[w_{i t} \mid \text { Dist.Cutof } f_{i}\right]-\lim _{\text {Dist.Cutoff } \uparrow 0} \mathbb{E}\left[w_{i t} \mid \text { Dist.Cutof } f_{i}\right]}{\lim _{\text {Dist.Cutoff } \downarrow 0} \mathbb{E}\left[g_{i} \mid \text { Dist.Cutof } f_{i}\right]-\lim _{\text {Dist.Cutoff } \uparrow 0} \mathbb{E}\left[g_{i} \mid \text { Dist.Cutof } f_{i}\right]}
$$

where $g_{i}$ is an indicator if worker $i$ graduated from an elite university, $t$ measures years of experience in the labor market, and $w_{i t}$ is the $\log$ (wages) after $t$ years of experience. Note that the parameter $\tau_{t}$ represents the local average treatment effect on earnings after $t$ years of experience for workers around the admission cutoffs that would enroll in a prestigious university if they were admitted (intent-to-treat effect). ${ }^{23}$

The employer learning-statistical discrimination RD test we propose consists of estimating if $\tau_{t}$ decreases with $t$. The test is based on the assumption that the unobserved ability $\left(\eta_{i}\right)$ is positively correlated to graduating from a selective university but is continuous around the admission cutoff. In this framework, assuming that firms do not observe Dist.Cutof $f_{i}$, they will use information on college prestige to predict that workers just above the admission cutoff have a higher $\eta_{i} \cdot{ }^{24}$ However, the wage differential between those above and below the cutoff should decline if firms learn the true

\footnotetext{
${ }^{22}$ Information on program admission cutoffs were collected at the universities websites (late application years) and newspapers (early application years). We find that $4 \%$ of individuals in our restricted sample with a prestigious university degree have weighted scores lower than the admission cutoffs. This could be justified by measurement errors in the admission cutoffs and weighs used in the paper or transfers from less prestigious universities. We drop these individuals from the sample used in the RD analysis.

${ }^{23}$ For a discussion of the relationship between regression discontinuity design and treatment effects, see Lee and Lemieux (2010)

${ }^{24}$ Note that in section 4 we also assume that firms cannot observe Dist.Cutof $f_{i}$. Furthermore, screening workers is expensive and firms learn fast (Lange (2007)), therefore it is not economically attractable to perform ability tests on recent college graduates.
} 
distribution of $\eta_{i}$ as workers gain experience and therefore should rely less on college prestige to set wages.

\subsection{Results}

We first address the empirical question if the probability of graduating from one of the two prestigious universities in Chile is discontinuous at the admission cutoff. Note that it is possible that individuals with a higher score than the admission cutoffs decided to attend a less prestigious university, which implies that we have a fuzzy regression discontinuity design. Figure 5 shows graphically the discontinuity in the probability of graduating from a prestigious university at the cutoff. From the figure, we find that the discontinuity in graduation from a prestigious university is approximately 60 percentage. This means that around $60 \%$ of the individuals with PAA scores just sufficiently high for admission choose to attend an elite university. Consequently, being just above the admission cutoff causes a large increase in the probability of graduating from a prestigious university in Chile, which is a necessary condition for the validity of the RD design.

Next, in figure 6 we present further evidence for the validity of the RD design. The basic idea is to test if there is a jump at the discontinuity for pre-treatment variables that should not be affected by the treatment. Precisely, if being above or below the cut-off is random, we should observe a zero treatment effect on the probability of being female or graduating from a private high school (Imbens and Lemieux (2008)). The figure suggests that there is no discontinuity of these variables around the cutoff. In fact, from a formal test using the same specification in columns (1) to (3) of table 6 but using female or private high school indicator as dependent variable, we cannot reject at reasonable levels of significance that there are zero effects of being above the cut-off on these pre-treatment outcomes. ${ }^{25}$

In order to present evidence of the effects of admission to a selective university on earning, we plot in figure 7 unconditional means of log annual earnings on the vertical axis and the distance from the admission cutoff on the horizontal axis for the first 4 years of labor market experience.

\footnotetext{
${ }^{25}$ Due to space constraint we omit the tests here, but they are available under request.
} 
The open circles represent 16 points local average and the lines represent linear fits of the data below and above the admission cutoff. The figure shows that there is a jump in earnings in the first year of labor market experience for workers who are just above the cutoff. This discontinuity is consistent with previous literature that finds a significant effect on earnings for being just above the admission cutoff of recent college graduates (Saavedra (2008)). However, as workers gain labor market experience, the discontinuity in earnings tend to decrease to the point that there is no apparent difference in terms of earnings between workers just above and just below the cutoffs four years after graduation. In addition to that, we observe that workers tend to be paid more in accordance with their weighted score as they accumulate experience in the market.

Table 6 presents further statistical evidence for discontinuity in earnings at the admission cutoff. In columns (1) to (3) of panel A of the table, we show that workers above the admission cutoff have on average $6-8 \%$ higher earnings than just below the admission cutoff in their first 10 years of labor market experience (varying little with bandwidth). In columns (4) to (7) we present specification that allows that the return to being approved at a selective university to change along a worker's career. Under this specification, we estimate a 10\%-14\% of wage premium for those above the cutoff in their first year of labor market experience, but this differential decreases by 1.5 to 2.7 percentage points per year of experience.

In Panel B of Table 6 we present the earnings discontinuity estimates taking into consideration that not all applicants with sufficiently high scores enroll in the top universities. For this purpose, we estimate an earnings equation using a two-stage least square method, where both graduating from a prestigious university and its interaction with experience are instrumented with an indicator for PAA scores above the admission cutoff and its interaction with experience. We estimate a 16-22\% effect of graduating from a selective university on earnings of recent college graduates. However, this gap decreases by 2.1-3.7 percentage points per year of experience in the labor market. Note that these estimates should be interpreted as the casual effect only for those applicants that would enroll in a prestigious university and graduate in the event of achieving a sufficiently high score (intent-to-treat effect). 
In order to provide a robustness checks for the main RD findings, we present in table 7 estimates for the earnings discontinuity at the admission cutoff and its interaction with experience for different model specifications. Precisely, we show in row (1) that our estimates are not sensitive to the exclusion of controls, which is expected if treatment is random around the admission cutoff. In rows (2) and (3) we test how our estimates change with different specifications for the distance from the admission cutoff. Finally we estimate our preferred model for males and females separately. While we estimate similar coefficients for these two groups, we do not find a significant change in the returns to being approved by a prestigious university with experience for women. We notice however that this result is due to large standard errors that might be explained by the fact that we have a smaller fraction of women in the restricted sample.

\section{Conclusion}

This paper tests whether firms statistically discriminate based on the selectivity of the university attended by workers. We first follow the employer learning statistical discrimination test suggested by Altonji and Pierret (2001) and show that the returns to graduating from an elite university in Chile decreases with experience and that the returns to hard-to-observe ability correlates increase with experience. These results are interpreted as evidence for statistical discrimination based on university selectivity.

Furthermore, we take advantage of the centralized admission process of traditional universities in Chile to propose a statistical discrimination test based on a regression discontinuity design. We show that recent graduates just above the admission cutoff to the most prestigious universities in Chile have significantly higher earnings than those just below the cutoff. However, as workers gain labor market experience, the earnings gap between these two groups decreases to the point that we cannot reject zero wage differentials 4 years after graduation. We interpret this result as firms paying workers in accordance with the selectivity of their college when they graduate from school, but rewarding them based on their true productivity as they reveal their quality to employers.

Our results shed some light on the benefits of graduating from a selective university. We interpret 
our findings as evidence that attending a prestigious university has a significant impact on signaling to firms a worker's unobservable quality. However, employers learn fast and individuals tend to be paid in accordance with their true ability as they gain experience in the labor market. 


\section{References}

Aigner, Dennis J. and Glen G. Cain (1977), 'Statistical theories of discrimination in labor markets', Industrial and Labor Relations Review 30(2), pp. 175-187.

Altonji, Joseph G. and Charles R. Pierret (2001), 'Employer learning and statistical discrimination', The Quarterly Journal of Economics 116(1), 313-350.

Arcidiacono, Peter, Patrick Bayer and Aurel Hizmo (2010), 'Beyond signaling and human capital: Education and the revelation of ability', American Economic Journal: Applied Economics pp. 76104.

Black, Dan A. and Jeffrey A. Smith (2006), 'Estimating the returns to college quality with multiple proxies for quality', Journal of Labor Economics 24(3), pp. 701-728.

Brewer, Dominic J, Eric R Eide and Ronald G Ehrenberg (1999), 'Does it pay to attend an elite private college? cross-cohort evidence on the effects of college type on earnings', Journal of Human Resources pp. 104-123.

Dale, Stacy Berg and Alan B. Krueger (2002), 'Estimating the payoff to attending a more selective college: An application of selection on observables and unobservables', The Quarterly Journal of Economics 117(4), 1491-1527.

Farber, Henry S. and Robert Gibbons (1996), 'Learning and wage dynamics', The Quarterly Journal of Economics 111(4), pp. 1007-1047.

Gibbons, Robert and Lawrence F Katz (1991), 'Layoffs and lemons', Journal of Labor Economics 9(4), 351-80.

Hastings, Justine S, Christopher A Neilson and Seth D Zimmerman (2013), Are some degrees worth more than others? evidence from college admission cutoffs in chile, Technical report, National Bureau of Economic Research. 
Hershbein, Brad (2013), 'Worker signals among new college graduates: The role of selectivity and gpa', Working Paper, Upjohn Institute .

Hoekstra, Mark (2009), 'The effect of attending the flagship state university on earnings: A discontinuity-based approach', The Review of Economics and Statistics 91(4), 717-724.

Hoxby, Caroline M (1998), 'The return to attending a more selective college: 1960 to the present', Unpublished manuscript, Department of Economics, Harvard University, Cambridge, MA .

Hu, Luojia and Christopher Taber (2011), 'Displacement, asymmetric information, and heterogeneous human capital', Journal of Labor Economics 29(1), 113-152.

Imbens, Guido W and Thomas Lemieux (2008), 'Regression discontinuity designs: A guide to practice', Journal of Econometrics 142(2), 615-635.

Kaufmann, Katja Maria, Matthias Messner and Alex Solis (2012), Returns to elite higher education in the marriage market: Evidence from chile, Technical report, Bocconi University working paper.

Lang, Kevin and Erez Siniver (2011), 'Why is an elite undergraduate education valuable? evidence from israel', Labour Economics 18(6), 767 - 777.

Lange, Fabian (2007), 'The speed of employer learning', Journal of Labor Economics 25(1), 1-35.

Lee, David S. and Thomas Lemieux (2010), 'Regression discontinuity designs in economics', Journal of Economic Literature 48(2), 281-355.

Mansour, Hani (2012), 'Does employer learning vary by occupation?', Journal of Labor Economics 30(2), 415-444.

Phelps, Edmund S. (1972), 'The statistical theory of racism and sexism', The American Economic Review 62(4), pp. 659-661.

Pop-Eleches, Cristian and Miguel Urquiola (2013), 'Going to a better school: Effects and behavioral responses', The American Economic Review 103(4), 1289-1324. 
Saavedra, Juan E. (2008), 'The returns to college quality: A regression discontinuity analysis', Unpublished manuscript, Harvard University, Cambridge, MA.

Schönberg, Uta (2007), 'Testing for asymmetric employer learning', Journal of Labor Economics $\mathbf{2 5}(4), 651-691$.

Spence, Michael (1973), 'Job market signaling', The Quarterly Journal of Economics 87(3), pp. $355-374$. 
Table 1: Descriptive Statistics for Selective and Non-Selective Universities

\begin{tabular}{|c|c|c|c|c|}
\hline \multirow{2}{*}{ Variables } & \multicolumn{2}{|c|}{ Selective Universities } & \multicolumn{2}{|c|}{ Non-selective Universities } \\
\hline & Mean & Std. Dev. & Mean & Std.Dev. \\
\hline Female & 0.53 & 0.5 & 0.56 & 0.5 \\
\hline Language PAA Score & 680.6 & 61.3 & 588.8 & 82.8 \\
\hline Math PAA Score & 715.9 & 68.6 & 609.4 & 103.4 \\
\hline High School Grade & 644.5 & 78.7 & 575.1 & 94.1 \\
\hline Private High School & 0.11 & 0.32 & 0.07 & 0.25 \\
\hline Number of Individuals & \multicolumn{2}{|c|}{11,554} & \multicolumn{2}{|c|}{46,923} \\
\hline
\end{tabular}

Table 2: Earnings for Selective and Non-Selective Universities

\begin{tabular}{lcc}
\hline Statistic & Selective Universities & Non-selective Universities \\
\hline Log of Annual Wage (in 1999 Pesos) & & \\
Mean & 15.58 & 15.19 \\
Std. Deviation & 1.09 & 1.16 \\
\hline Observations & 61,844 & 251,233 \\
\hline
\end{tabular}

Note: See section 3 for definition of selective university. 


\section{Table 3: Traditional EL-SD Regression}

Dependent Variable: Log Annual Wage

\begin{tabular}{lccc}
\hline Model & $(1)$ & $(2)$ & $(3)$ \\
\hline Variables & & & \\
Selective University & 0.196 & 0.220 & 0.242 \\
& $(0.00865)^{* * *}$ & $(0.0110)^{* * *}$ & $(0.0115)^{* * *}$ \\
Selective University x Experience & & -0.00893 & -0.0168 \\
& & $(0.00268)^{* * *}$ & $(0.00296)^{* * *}$ \\
PAA Language & 0.0312 & 0.0312 & 0.0291 \\
& $(0.00417)^{* * *}$ & $(0.00417)^{* * *}$ & $(0.00556)^{* * *}$ \\
PAA Math & 0.0747 & 0.0747 & 0.0545 \\
& $(0.00487)^{* * *}$ & $(0.00487)^{* * *}$ & $(0.00616)^{* * *}$ \\
PAA Language x Experience & & & 0.000879 \\
& & & $(0.00134)$ \\
PAA Math x Experience & & & 0.00717 \\
& & & $(0.00133)^{* * *}$ \\
Constant & 13.04 & 13.03 & 13.17 \\
& $(0.114)^{* * *}$ & $(0.114)^{* * *}$ & $(0.116)^{* * *}$ \\
Observations & & & \\
R-squared & 307,864 & 307,864 & 307,864 \\
\hline
\end{tabular}

Controls: Female, Cubic Experience Polynomial, Major Dummies, and Year Dummies.

White/Huber standard errors clustered at the individual level are reported in parentheses

*** $p<0.01, * * p<0.05, * p<0.1$

Note: Math and Language PAA are standardized by test year. See section 3 for definition of selective university. 
Table 4: Traditional EL-SD Regression, Robustness Check Dependent Variable: Log Annual Wage

\begin{tabular}{|c|c|c|}
\hline Model & (1) & $(2)$ \\
\hline \multicolumn{3}{|l|}{ Variables } \\
\hline \multirow[t]{2}{*}{ Selective University } & 0.235 & 0.242 \\
\hline & $(0.0115)^{* * *}$ & $(0.0115)^{* * *}$ \\
\hline \multirow[t]{2}{*}{ Selective University x Experience } & -0.0141 & -0.0168 \\
\hline & $(0.00296)^{* * *}$ & $(0.00296)^{* * *}$ \\
\hline \multirow[t]{2}{*}{ PAA Language } & 0.0283 & 0.0292 \\
\hline & $(0.00556)^{* * *}$ & $(0.00556)^{* * *}$ \\
\hline \multirow[t]{2}{*}{ PAA Math } & 0.0643 & 0.0553 \\
\hline & $(0.00623)^{* * *}$ & $(0.00617)^{* * *}$ \\
\hline \multirow[t]{2}{*}{ PAA Language $x$ Experience } & 0.00133 & 0.000831 \\
\hline & $(0.00134)$ & $(0.00134)$ \\
\hline \multirow[t]{2}{*}{ PAA Math $x$ Experience } & 0.00359 & 0.00689 \\
\hline & $(0.00138)^{* * *}$ & $(0.00134)^{* * *}$ \\
\hline \multirow[t]{2}{*}{ Female $x$ Experience } & -0.0245 & \\
\hline & $(0.00225)^{* * *}$ & \\
\hline \multirow[t]{2}{*}{ Private High School x Experience } & & 0.0120 \\
\hline & & $(0.00490)^{* *}$ \\
\hline \multirow[t]{2}{*}{ Constant } & 13.08 & 13.17 \\
\hline & $(0.117)^{* * *}$ & $(0.116)^{* * *}$ \\
\hline Observations & 307,864 & 307,864 \\
\hline R-squared & 0.245 & 0.245 \\
\hline \multicolumn{3}{|c|}{ Controls: Female, Cubic Experience Polynomial, Major Dummies, and } \\
\hline \multicolumn{3}{|c|}{$\begin{array}{l}\text { White/Huber standard errors clustered at the individual level are } \\
\text { reported in parentheses }\end{array}$} \\
\hline \multicolumn{3}{|l|}{$* * * p<0.01, * * p<0.05, * p<0.1$} \\
\hline
\end{tabular}

Note: Math and Language PAA are standardized by test year. See section 3 for definition of selective university. 
Table 5: Traditional EL-SD Regression - University Quality Index Dependent Variable: Log Annual Wage

\begin{tabular}{|c|c|c|c|}
\hline Model & (1) & (2) & (3) \\
\hline \multicolumn{4}{|l|}{ Variables } \\
\hline \multirow[t]{2}{*}{ University Quality Index } & 0.089 & 0.099 & 0.113 \\
\hline & $(0.00395)^{* * *}$ & $(0.00492)^{* * *}$ & $(0.00533)^{* * *}$ \\
\hline \multicolumn{2}{|c|}{ Univer. Quality Index x Experience } & -0.0034 & -0.0084 \\
\hline & & $(0.00109)^{* * *}$ & $(0.00132)^{* * *}$ \\
\hline \multirow[t]{2}{*}{ PAA Language } & 0.0275 & 0.0274 & 0.0246 \\
\hline & $(0.00421)^{* * *}$ & $(0.00421)^{* * *}$ & $(0.00560)^{* * *}$ \\
\hline \multirow[t]{2}{*}{ PAA Math } & 0.0568 & 0.0567 & 0.0333 \\
\hline & $(0.00507)^{* * *}$ & $(0.00507)^{* * *}$ & $(0.00649)^{* * *}$ \\
\hline \multirow[t]{2}{*}{ PAA Language $x$ Experience } & & & 0.0011 \\
\hline & & & $(0.00134)$ \\
\hline \multirow[t]{2}{*}{ PAA Math $x$ Experience } & & & 0.0084 \\
\hline & & & $(0.00143)^{* * *}$ \\
\hline \multirow[t]{2}{*}{ Constant } & 12.62 & 12.54 & 12.61 \\
\hline & $(0.115)^{* * *}$ & $(0.117)^{* * *}$ & $(0.117)^{* * *}$ \\
\hline Observations & 302,417 & 302,417 & 302,417 \\
\hline R-squared & 0.245 & 0.245 & 0.245 \\
\hline \multicolumn{4}{|c|}{$\begin{array}{l}\text { Controls: Female, Cubic Experience Polynomial, Major Dummies, and Year Dummies. } \\
\text { White/Huber standard errors clustered at the individual level are reported in } \\
\text { parentheses } \\
* * * p<0.01,{ }^{* *} p<0.05,{ }^{*} p<0.1\end{array}$} \\
\hline
\end{tabular}

Note: University quality index is the score awarded to colleges by the "Que Pasa" ranking of 2011 and is measured in standard deviations. Math and Language PAA are standardized by test year. 
Table 6: EL-SD Regression Discontinuity Test

Dependent Variable: Log Annual Wage

\begin{tabular}{|c|c|c|c|c|c|c|}
\hline \multirow[t]{3}{*}{ Panel A } & \multicolumn{6}{|c|}{ Reduced Form } \\
\hline & \multicolumn{3}{|c|}{ Bandwidth (Points from Cutoff) } & \multicolumn{3}{|c|}{ Bandwidth (Points from Cutoff) } \\
\hline & 125 & 100 & 75 & 125 & 100 & 75 \\
\hline Model & (1) & $(2)$ & (3) & (4) & $(5)$ & (6) \\
\hline \multirow[t]{2}{*}{ Approved at Selective University } & 0.081 & 0.073 & 0.065 & 0.143 & 0.119 & 0.099 \\
\hline & $(0.0287)^{* * *}$ & $(0.0308) * *$ & $(0.0342)^{*}$ & $(0.0330) * * *$ & $(0.0348) * * *$ & $(0.0382) * * *$ \\
\hline \multirow[t]{2}{*}{ Approved at Selective Univ.* Experience } & & & & -0.027 & -0.020 & -0.015 \\
\hline & & & & $(0.0071) * * *$ & $(0.0073)^{* * *}$ & $(0.0078)^{*}$ \\
\hline Observations & 39,748 & 36,639 & 31,843 & 39,748 & 36,639 & 31,843 \\
\hline R-squared & 0.135 & 0.128 & 0.120 & 0.135 & 0.128 & 0.120 \\
\hline \multirow[t]{3}{*}{ Panel B } & \multicolumn{6}{|c|}{2 Stages Least Square } \\
\hline & \multicolumn{3}{|c|}{ Bandwidth (Points from Cutoff) } & \multicolumn{3}{|c|}{ Bandwidth (Points from Cutoff) } \\
\hline & 125 & 100 & 75 & 125 & 100 & 75 \\
\hline Model & (1) & $(2)$ & (3) & (4) & (5) & $(6)$ \\
\hline \multirow[t]{2}{*}{ Graduated from Selective University } & 0.133 & 0.122 & 0.110 & 0.222 & 0.189 & 0.160 \\
\hline & $(0.0470) * * *$ & $(0.0512)^{* *}$ & $(0.0576)^{*}$ & $(0.0525)^{* * *}$ & $(0.0565)^{* * *}$ & $(0.0629)^{* *}$ \\
\hline \multirow{2}{*}{\multicolumn{4}{|c|}{ Graduated from Selective Univ.* Experience }} & -0.037 & -0.028 & -0.021 \\
\hline & & & & $(0.0098) * * *$ & $(0.010)^{* * *}$ & $(0.0109)^{*}$ \\
\hline Observations & 39,748 & 36,639 & 31,843 & 39,748 & 36,639 & 31,843 \\
\hline R-squared & 0.140 & 0.133 & 0.125 & 0.140 & 0.134 & 0.126 \\
\hline
\end{tabular}

Approved at Selective Univ.: Points from the Cutoff $>=0$

Controls: Points from the Cutoff, and Interaction of Points from the Cutoff with Approved at Prestigious Univ., Female, Cubic Experience Polynomial, Major Dummies, and Year Dummies.

Instrument in Panel B: In columns (1)-(6) the endogenous variables are intrumented with Approved at Prestigious University and in columns (4)-(6) also with its interaction with experience

White/Huber standard errors accounting clustered at the individual level are reported in parentheses *** $p<0.01, * * p<0.05, * p<0.1$

Note: The sample is restricted to individuals with engineering, business, medical and law degree (see section 5 for details). 


\section{Table 7: EL-SD Regression Discontinuity Test - Robustness Checks}

Dependent Variable: Log Annual Wage, Applicants within 100 points from Cutoff

\begin{tabular}{|c|c|c|c|c|c|c|}
\hline \multirow[b]{2}{*}{$\begin{array}{l}\text { Regression } \\
\text { Specification }\end{array}$} & \multirow[b]{2}{*}{$\begin{array}{l}\text { Additional } \\
\text { Controls }\end{array}$} & \multirow[b]{2}{*}{$\begin{array}{l}\text { Function of } \\
\text { Points from } \\
\text { the Cutoff }\end{array}$} & \multirow[b]{2}{*}{$\begin{array}{c}\text { Flexible } \\
\text { Coefficient? }\end{array}$} & \multirow[b]{2}{*}{ Sample } & \multicolumn{2}{|c|}{ Estimated Coefficients } \\
\hline & & & & & $\begin{array}{l}\text { Approved at } \\
\text { Selective } \\
\text { University }\end{array}$ & $\begin{array}{c}\text { Approved at } \\
\text { Selective Univ.* } \\
\text { Experience }\end{array}$ \\
\hline (1) & No & Linear & Yes & All & $\begin{array}{c}0.130 \\
(0.0354)^{* * *}\end{array}$ & $\begin{array}{c}-0.019 \\
(0.0075)^{* *}\end{array}$ \\
\hline$(2)$ & Yes & Cubic & No & All & $\begin{array}{c}0.103 \\
(0.0426)^{* *}\end{array}$ & $\begin{array}{c}-0.020 \\
(0.0073)^{* * *}\end{array}$ \\
\hline (3) & Yes & Cubic & Yes & All & $\begin{array}{c}0.109 \\
(0.0425)^{* *}\end{array}$ & $\begin{array}{c}-0.020 \\
(0.0073)^{* * *}\end{array}$ \\
\hline (4) & Yes & Linear & Yes & Males & $\begin{array}{c}0.100 \\
(0.0427)^{* *}\end{array}$ & $\begin{array}{c}-0.018 \\
(0.0086)^{* *}\end{array}$ \\
\hline (5) & Yes & Linear & Yes & Females & $\begin{array}{c}0.153 \\
(0.0599)^{* *}\end{array}$ & $\begin{array}{c}-0.022 \\
(0.0135)\end{array}$ \\
\hline
\end{tabular}

All specifications include Cubic Experience Polynomial.

Approved at Selective Univ.: Points from the Cutoff $>=0$

Additional Controls: Female, Major Dummies, and Year Dummies.

Flexible coefficient indicates whether the estimated coefficients of points from cutoff was allowed to differ on each side of the admission cutoff

White/Huber standard errors clustered at the individual level are reported in parentheses

$* * * p<0.01, * * p<0.05, * p<0.1$

Note: The sample is restricted to individuals with engineering, business, medical and law degree (see section 5 for details). 
Figure 1: Application Process to Traditional Universities

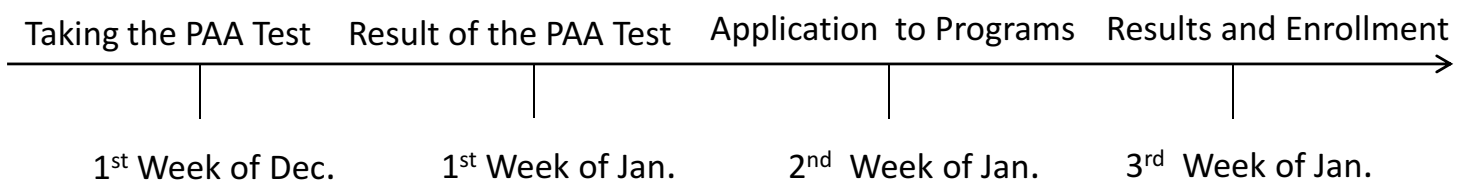

Figure 2: Smoothed Language PAA Score Distribution

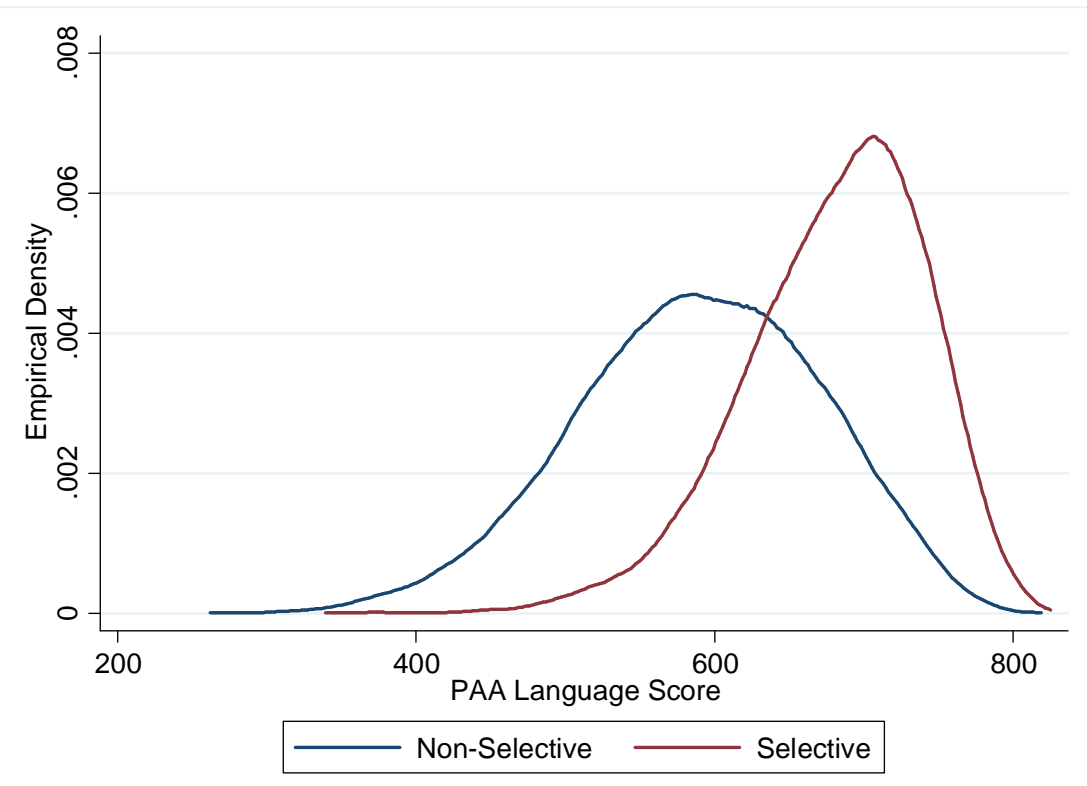

Note: Language PAA is a component of the centralized test for admission to university in Chile. See section 3 for definition of selective university. 
Figure 3: Smoothed Math PAA Score Distribution

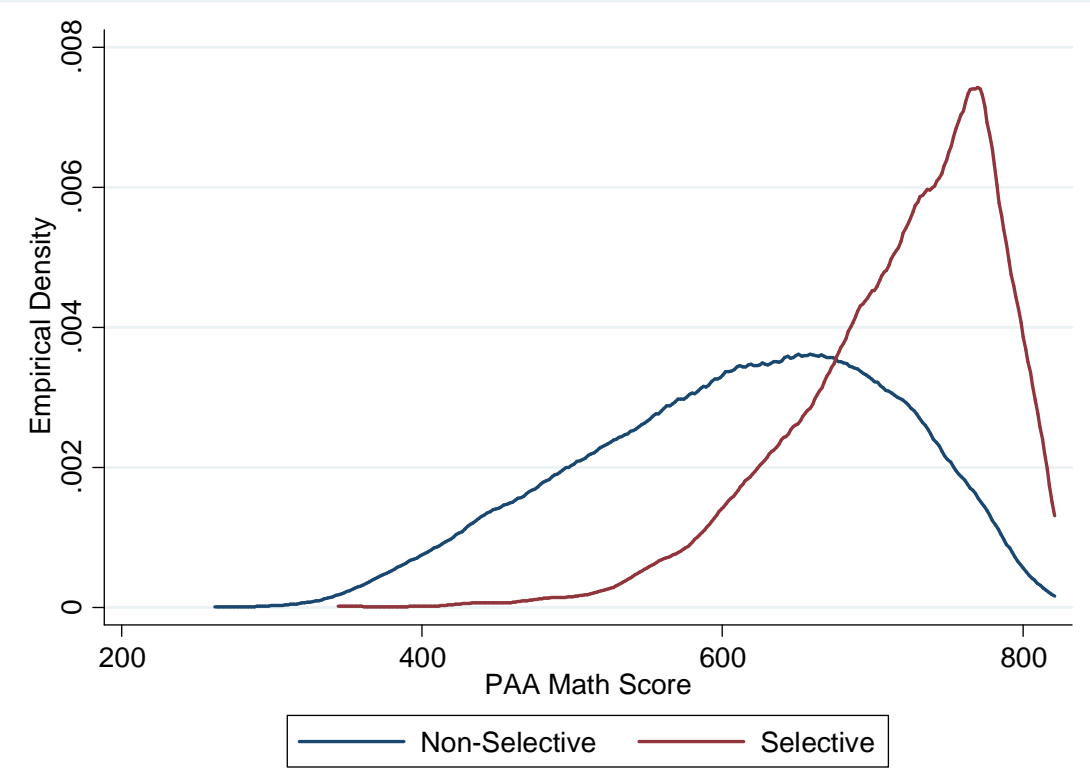

Note: Math PAA is a component of the centralized test for admission to university in Chile. See section 3 for definition of selective university. 
Figure 4: Selective University Premium by Experience Level

\section{Selective University Coefficients}

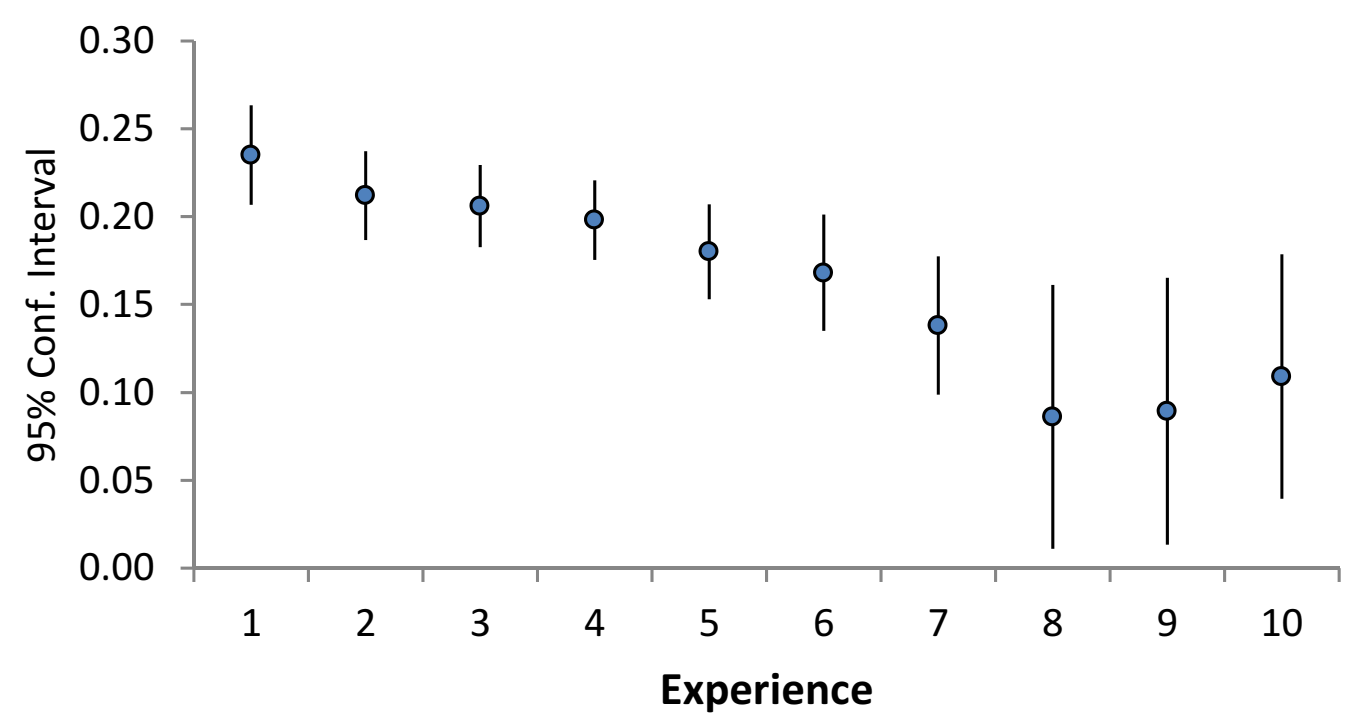

Note: Each circle represents the effect of the selective university dummy estimated by linear least squares within each of the 10 experience groups. The controls used in the regressions are the same as those presented in Tables 3 and 5 (including Math and Language PAA scores). Confidence intervals are calculated using White/Huber heteroscedasticity standard errors. 
Figure 5: Graduation from Selective University Discontinuity

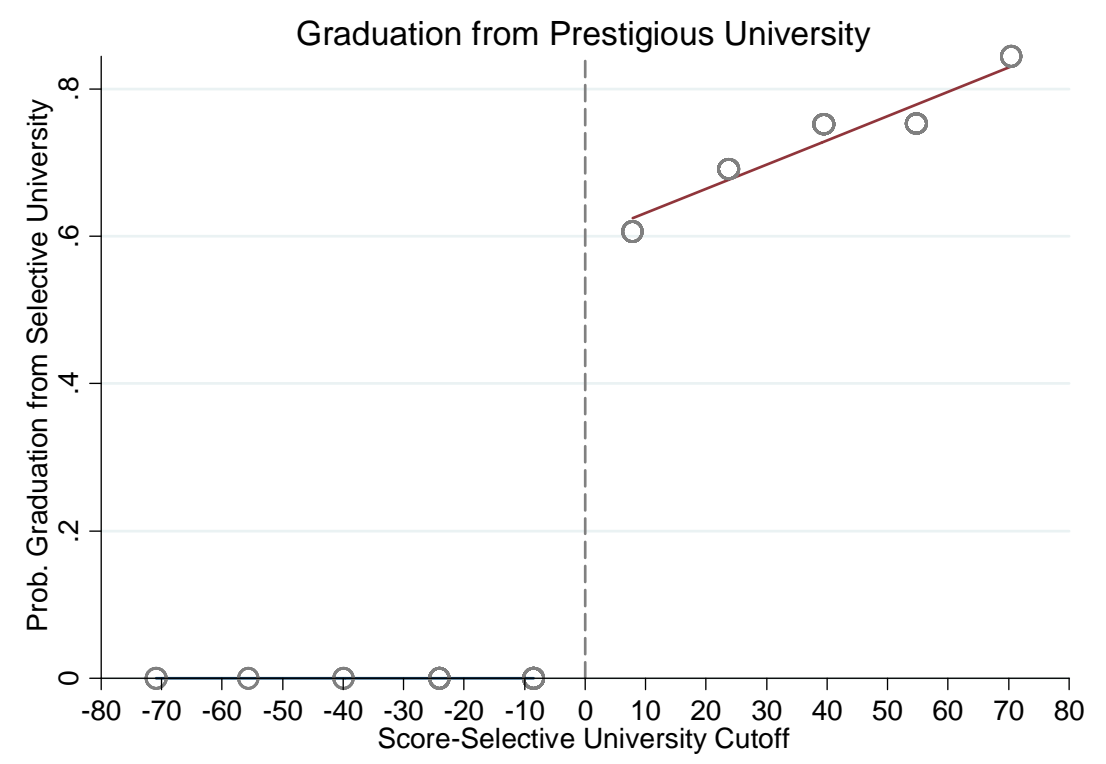

Note: Open circles represent 16 points local averages and the lines are local linear fits below and above the admission cutoff. The sample is restricted to individuals with engineering, business, medical and law degrees (see section 5 for details). 


\section{Figure 6: Discontinuity at Pre-treatment Outcomes}
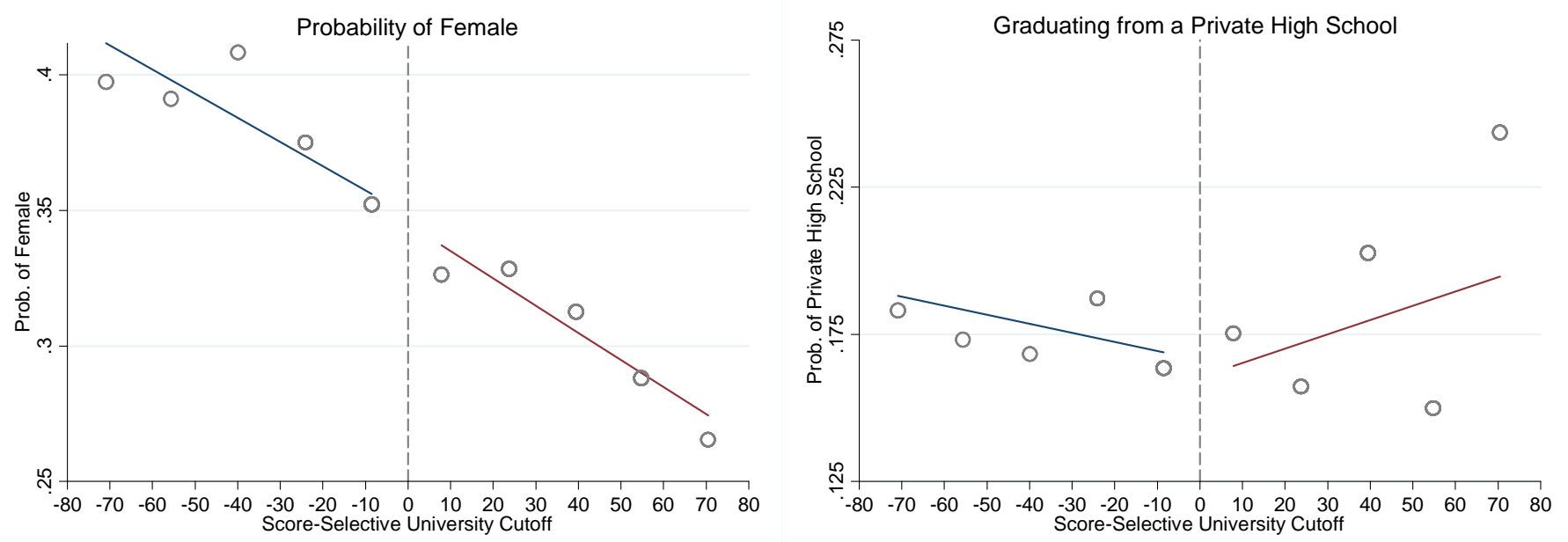

Note: Open circles represent 16 points local averages and the lines are local linear fits below and above the admission cutoff. The sample is restricted to individuals with engineering, business, medical and law degrees (see section 5 for details). 
Figure 7: Earnings Discontinuity by Experience
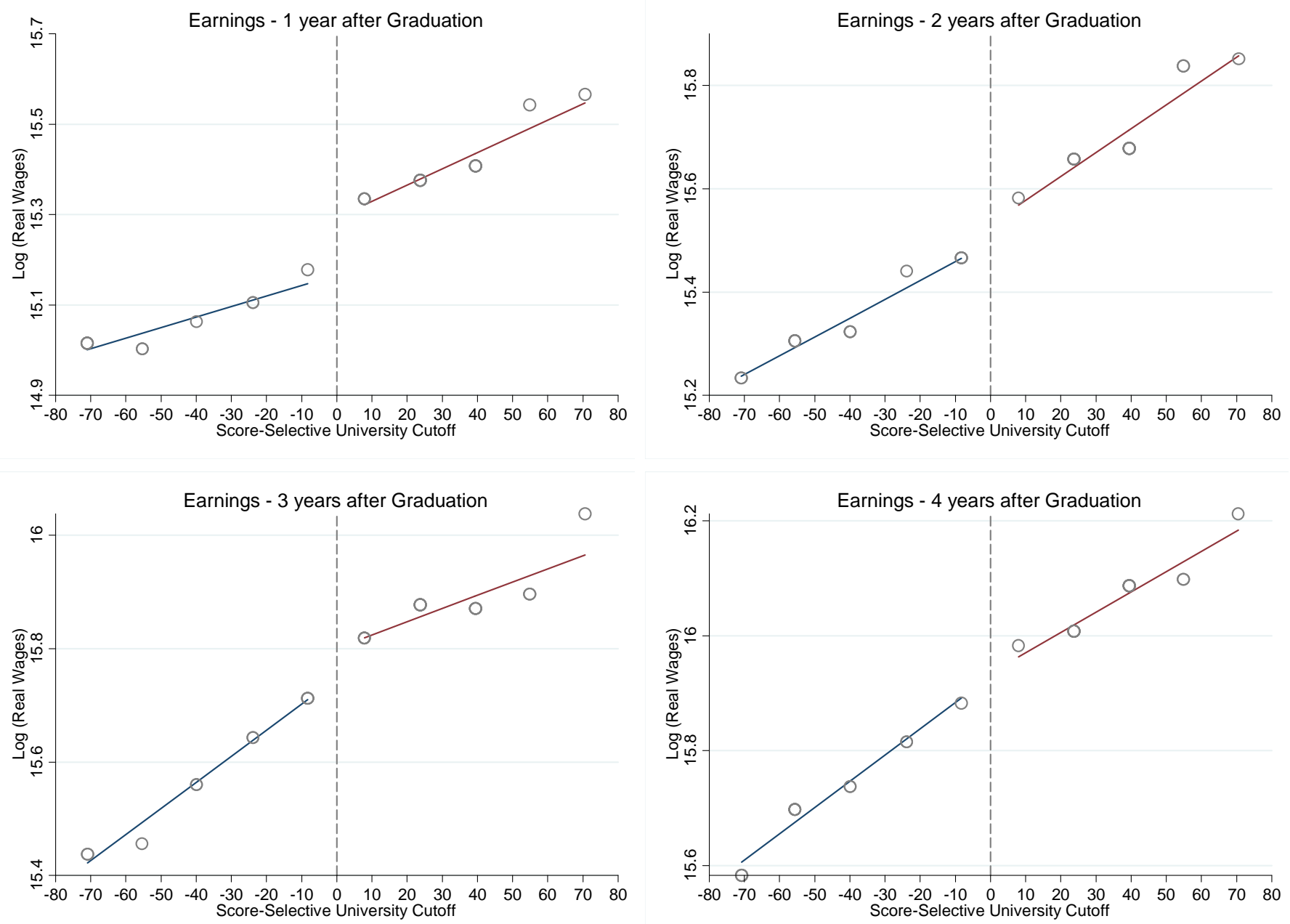

Note: Earnings are defined as log annual wages measured in real Chilean pesos. Open circles represent 16 points local averages and the lines are local linear fits below and above the admission cutoff. The sample is restricted to individuals with engineering, business, medical and law degree (see section 5 for details). 